bei Zutritt der Luft leicht zersetat. Der mit dem Kalk verbundene Süirholzzucker setzt an der Luft vollkommen kry. stallisirten kohlensauren Kalk ab, analog dem aus dem Kalksacharat erhaltenen. Der Mannit, so wie man ihn aus seiner alkoholischen Auflösung erhält, verbindet sich mil einer ziemlich grofsen Menge Kalk; die Auflösung ist gelb; ich fand aber, dalis diese Färbung vou einer Verbindung des Kalka mit einer harzartigen oder öligen Materie herrühr, die mit dem Maunit verbunden bleibt und die man durch wiederholte Behandlung des letzteren mit kochendem Aether abscheiden kann. Die grofse Menge Kalk, die sich mit dem Mannit verbindet; ist durch die Gegenwart dieses Oels bedingt; denn mehrmals aus Alkohol krystallieirter Mannit zeigt keine Fïrbung mehr und der Kalk wird nicht mehr in Verbindnng zurückgehalten.

\title{
Ueber das Wasser bei einigen chemischen Reactionen;
} von Demselben.

Der Einfiufs, welchen die Gegenwart des Wassers bei einigen chemischen Keactionen ausibt, war schon mehrmals der ' Gegenstand wichtiger Beobachtungen. Proust fand, daff Salpetersäure von 1,410 spec. Gewicht das $Z$ inn nicht angreift und dals bei Zusatz vou ein wenig Wassser, diese Säure die energischste Wirkung ausübt. Neverlich stellte Pelouze, unter anderen Thatsachen. (est, 1) dafs Essigsäure von 1,063 spec. Gew. kohlensauren Baryt nicht zersetzt; 2) dafs die kohlen. sauren Salze des Kali's, Natron's, Bleis, Zink's, Sirontians, Baryts und Magnesia durch krystallisirbare Essigsäure zwar zer- 
setzt werden,.dafs aber die Energie der Wirkung gröfser ist bei Zusatz von Wasser und dafs díe Wirkung auf diese kohlensauren Salze gleich Null ist, wenn man die Süure in absoIntem Alkohol auflöst; dafs endlich wasserfrejer Alkohni, Schwefeläther, Essigäther die Eigensehafteu selbat der măchtigsten Säuren vollkommen maskiren: ihre Auflösung in diesen Fliissigkeiten röthet Lakmus nicht und zersetzt eine grofse Gahl von kohlensauren Salzen nicht.

„Die rationelle Erklärung einer so bizarren Thatsache (der Nichteinwirkung von mit Alkohol genischter Essigsäure auf kohlensaures Kali), sagt Pelouze, scheint mir nicht leicht zu finden. Man kann hier nicht annehmen, dafs sich Unlöslichkeit der Bitdung des essigsauren Kali's widersetze, deni dieses Salz ist löslich nicht allein in Alkohol, sondern auch in einem Gemenge von Alkohol und Essigsäure.“

An diese Beobachtungen reihen sich noch andere von Braconnot; sie betreffen besonders die Salpetersäure. „Diese Slure wirkt, concentrirt und kochend, durchaus nicht weder suf Stücke ron weifrem Marmor, noch auf grepulverten kohlensauren Baryt.“ Diese Nichtein wirkung wird von ilım der UnIöslichkeit des salpetersauren Kalks und Baryts in concentrirter Salpeterë̈ure und der Affinität, die die Kohlensäure in ihren Verbindungen festhält, zugeschrieben. Braconnot stellt ouf eine triftig scheinende Weise selbst fest, dafs, wenn weder Zinn, noch Eisen, Silber oder Blei durch concentrirte Salpetersäure angegriffen werien, diefs nur daher rührt, weil die salpetersauren Salze dieser Metalle in dieser Säure anlöslich sind. Der nemlichen Ursache will er alle von Pelouze erhaltenen Resultate zuschreiben.

Nachstehende neue Thatsachen beweisen inders, wie ich glaube, dafis diese Erklärung von Braconnot nicht für alle Falle angenommen werden kann, und dafs andere als die au- 
24 Kuhlmann, üb. das Wasser bei Einigen chem. Reactionen.

geführten Motive sich oft der Wirkung der Süuren auf dio Basen oder deren kohlensauren Salze entgegenslellen.

Gine der auffallendaten chemischen Reactionen ist die, welche bei Berïhrung von Schwefelsäure mit Baryt eintritt. Man weif, dofs die Verbindung bisweilen unter soloher Wärmeentwickclung vor sich geht, dafs die Masse des Baryts gliihend wird, und dafs ein Theil der Schwefelsäure als Dampf entweicht. Ich beobachtete, bei Gelegenheis dieser Verbindung, Sonderbarkeiten, die mir einiges wissenschaftliche Interesse darzubieten scheinen.

A. Bringt man in der Kälte ein Stück Baryt mit rauchender Schwefelsäure zusammen, so tritt bald eine sehr lebhafte Reaction ein. Diese Wirkung iet energischer noch, wenn man wasserfreie, bei ohngefähr $25^{\circ}$ Hüssig gemachte Schwefelsäure anwendet.

B. Ein frisch geglïhtes Stïck Baryt, in Beriihrang gebracht mit Schwefelsäurehydrat, das uur ein Atom Wasser enthält (von 1,848 spec. Gew.) erleidet keine Veränderung; es tritt kein Zeichen von. Verbindung ein. Setat man das Gemenge der feuchten Luft aus, so findet nach einiger Zeit oogleich Einwirkung statt; sie kann sogleich hervorgerufen werden, wenn man den mit Schwefelsäure befeuchteten Baryt an einem einzigen Punkt mit einem heifsen Eisen oder einem vorher in Wasser getauchten Glasstabe beriibrt.

C. Bringt man ein Stuick Baryt in der Kälce mit Schwefelsänrehydrat von 1,848 spec. Gew., dem man vorher eine sehr geringe Menge Wasser zngesetzt hat, in Berührung, so tritt sogleich Gluihen ein. Die Wirkung ist cben so rasch, wenn man schwächere Säure anwendet; das Glühen tritt aber nicht ein.

D. Schwefelsäure von 1,848 spec. Gew., die auf frisch geglühten Baryt in der Kälte keịe Wirkung hat, wirkt mit Hef- 
Kuhlmunn, üb. das Wasser bei einigen vhom Rouctionen. 25

tigkeit auf Baryt, der etwas Feuchtigkeit aus der Luft angezogen hat.

F. Sciw efelsäurehydrat, das hinlänglich verdunnt ist, um unmittelbar auf Baryt zu wirken, übt in der Kälte keine Wirkung mehr aus, wein es mit absolutem Alkohol, Aether oder Holzgeist gemischt ist.

Aus diesen abweichenden Resultaten mufs man schliefsen, dafs in dem, ein At. Wasser enthaltenden, Schwefelsäurehydrat, das Wasser nur schwierig aus seiner Verbindung entfernt werden kann; es neutralisirt in gewisser Art die Eigenschaften der Säure, denn selbst bei Gegenwart einer so mächtigen Base wie Baryt, wirkt die Säure uur unter Beihülfe einer höheren Temperatur.

Wenn man bei chemischen Reoctionen von dieser Säure Gebranch macht, so wird es von Wichtigkeit das spec. Gew. genau anzugeben, denn aus obigen Versnchen kuna man erwehen, dafs sie sich mit Energie mit Baryt verbindet, wenn man sie mit dieser Base bei zewöhnlicher Temperatur im wasserfreien Zustande, ranchend oder endlich yon geringerer Dichtigkeit als 1,848 in Beriihrung bringt; dafs sie aber zu wirken aufhört, wenn sie genau die Dichtigkeit von 1,918 hat.

Wenn die wasserleere oder die rauchende Säure sich nicht mit einer grofsen Heftigkeit mit den Baryt verhänden, so könnte man, (um die Nothwendigkeit, die Säure von 1,849 opec. Gew. zu verdïnen zu rechtfertigen), annehmen, dafs die Bildung des schwefelsanren Baryts nur Statt finden kann bei der vorgängigen Bildung von Barythydrat auf Kosten eines Antheịls, in seiner Verbindung mit Schwefelsäure schwach zurückgehaltenen, Wassers; aber beim Vorliegen der bezeichneten Thatsacheu ist diese Ansicht nicht zulässig. Bei Anwendung von Säure von 1,94\% ${ }^{\circ}$ pec. Gew. wird die Reaction durch Wãrme so gut wie durch Zusatz von etwas Wusser hervorgorufon, und in letzterem Fall bedingt die Gegenvart des Was- 
sers ohne Zweifel nur die Entwickelung der nothwendigen Wärme. Diese Entwickelung kann von verschiedenen Ursachen herrihren: in dem Versuch C. kann sie der Verbindung eines Antheils Wasser der schwachen Säure mit dem Baryt, oder der Bildung des Barythydrats, zugeschrieben werden und in dem Versuch $D$.ist es das fertig gebildete Barythydrat, welches, der Verbindung günstiger, sogleich bei seiner Berührung mit Schwefelsäure ron 1,848 spec. Gew. schwefelsauren Haryt bildet.

Die ron Braconnot gegebenen Firklärangen ron der Nichteinwirkung der Säuren auf die Metalle, die Basen oder kohlensauren Sulze unter gewissen Umständen, lassen sich auf die Resultate der beschriebenen Versuche nicht anwenden; sie sind gleichfalls ungenügend zur Erklärung der von Pronst beobachteten Erscheinung, bei der Finwirkung ron Salpetersăure auf Zinn, wobei die Bildung einer unlöslichen Verbindung stattfindet, selbst wenn die Saure in dem xur energischen Wirkung günstigsten Zustande ist. Ich glaube, dars bei allen ron Prouet, Pelouze und Braconnot bezeichneten Reactionen die grofse Stabilität der Verbindungen der Sturen mit Wasser, wenn diese Verbindungen nach ihrem Atomverhältnifs Stalt haben, einen grofsen Einflufs ansubt und dafs die Beimischung ron Alkohol oder Aether qu den Säuren zum Resultat hat, nicht allein eine Fliissigkeit zo geben, worin das bei Reaction dieser Säuren auf die Basen oder kohlensauren Salze entstehen krïnnende Produkt unauföslich ist, sondern auch die Verhinderung ron jeder Einwirkung, indem síe den Säuren die Antheile Wasser entxiehen, welche nicht chemisch gebunden sind. Der Versuch E dient zur Stütze dieser Ansicht.

Bein Zusammenbringen son Salpetersäure mit Metallen erleichtert ohne $Z$ weifel die Gegenwart ron einer geringen Menge nicbt verbundenen Wassers auch dic Reaction. Das 
Ammoniak, desseu Bildung ich, wie bei dem Zinn, beim Eisen, Zink und Kadmium beatätigt habe, lăfat diefs vermuthen, aher diesor Einflurs ist nicht leicht anzunehmen bei dem Blei, Knpfor und Silber.

Im Laufe dieser Versuche fand ich, dafs die Wirknng der Salpetersäure auf die Metalle immer von der Bildung einet mehr oder wenigeı beträchtlichen Menge Ammoniak bugleitet ist, je nach den Eigenschaften der Metalle das Wasser mehr oder minder leicht zu zersetzen. Die Metalle, welche das Wasser nicht zersetzen, liefern keine Spur Ammoniak.

Bei Kalium und Natrium erhielt ich indefs kain salpetersaures Ammoniak, was ich der hohen Temperatur zuschreibe, welche entsteht. und wobei das salpetersaure Ammoniak nicht bestehen kann. Die Versuche mit den Alkalimetallen sind nicht ohne Gefahr, wegen der heftigen Lxplosionen, die im Moment der Berührung dieser Metalle mit Salpetersäure eintreten.

\section{$=$ \\ Bereitung von ätzendem Baryt; von Dr. Fr. Mohr.}

Durch die Methode den salpetersauren Baryt oline frefe Salpetersïure zu bereiten*) stellt sich auch die Darstellung des ätzenden Baryts aus diesem Salze viel kürzer und vortheilhefter heraus, als jene nach Vogel mit Kupferoxyd. Das bei letzterer Methode gehildete Schwefelkupfer lärst sich nämlich nicht mehr zu demselben $Z$ wecke gebrauchen, oder zubereiten, indem es beim Glühen in schwefelsaures Salz

Thnal, d. Pharm. Bd. 25. S. 290. 